\title{
PREVENINDO PNEUMONIA NOSOCOMIAL: CUIDADOS DA EQUIPE DE SAÚDE AO PACIENTE EM VENTILAÇÃO MECÃNICA INVASIVA*
}

\author{
PREVENTION OF NOSOCOMIAL PNEUMONIA: HEALTH TEAM INTERVENTION ON A PACIENT WICH \\ MECHANICAL VENTILATION*
}

\section{HACIENDO LA PREVENCIÓN DE LA NEUMONÍA NOSOCOMIAL: CUIDADOS EL CUADRO DE SALU AL PACIENTE EM VENTILACIÓN MECÁNICA INVASIVA*}

\section{Izaura Luzia Silvério Freire ${ }^{1}$, Glaucea Maciel de Farias ${ }^{2}$, Cristiane da Silva Ramos $^{3}$}

RESUMO: Estudo exploratório e descritivo de abordagem quantitativa, realizado na Urgência e UTI, com vistas a identificar os cuidados prestados pelos profissionais e a associação entre a VM e 0 aparecimento de pneumonia. A população foi de 68 profissionais. Dos 38 pacientes intubados, 17 foram a óbito e 4 extubados antes de completarem 48 horas; 13 tiveram diagnóstico de PAVM, 4 com 72 horas e 9 após esse período. Feito cultura de secreção traqueal em 10 pacientes cuja etiologia mais freqüente foi a Pseudomonas aureus. Quanto aos cuidados realizados antes da VM nos ventiladores mecânicos, circuitos respiratórios e umidificadores, em 25 não foram realizadas a limpeza e desinfecção; 21 foram montados sem técnica asséptica; no momento da instalação o ventilador foi testado 26 vezes com pulmão não estéril; o condensado, presente em 87 vezes foi descartado em 70; 52 vezes os profissionais não lavaram as mãos após esse procedimento; em 11 das 17 intubações, o médico não lavou as mãos antes; nenhum utilizou EPI; das 313 aspirações, em 249 as mãos não foram lavadas antes; das 176 dietas introduzidas, em 141 vezes não houve interrupção durante a aspiração; 232 vezes o soro fisiológico estava estéril; em menos da metade, as mãos foram lavadas após; a fisioterapia respiratória foi realizada 70 vezes e desses, em 45, os profissionais não realizaram lavagem prévia das mãos; 33 não interromperam a dieta. Predominou a mudança de decúbito no horário da manhã. Concluímos que dos 17 pacientes que permaneceram no estudo, 13 tiveram diagnóstico de PAVM entre 48 e após 72 horas de uso da VM e os dados obtidos nas observações estruturadas sinalizam para o risco desses pacientes terem PAVM.

PALAVRAS CHAVE: Infecção Hospitalar; Pneumonia Nosocomial; Ventilação Mecânica.

ABSTRACT: Descriptive exploratory study, prospective with quantitative approach, in Emergency Hospital Intensive Care and Emergency Units, aimed at identifying the association between MV the care given by professionals and the occurrence of pneumonia. The population was of 68 professionals. The results show that from the 38 intubated patients, 17 died and 04 were extubated before the first 48 hours of their admission; 13 were diagnosed with MVAP, 04 within 72 hours and 09 after that period. The tracheal secretion culture was performed on 10 patients and the most frequent etiological agent was pseudonomas aureus. As for the procedures performed before MV on the mechanical ventilators, respiratory and moisturizing circuits, on 25 cleansing and disinfection was not performed; 21were assembled without asseptic techiques; after assembly, the ventilator was tested 26 times with non-sterile lungs; the condensation when present (87 times) was discarded on 70; on 52 times the professionals did not wash their hands after this procedure; on 11 from the 17 intubations, the physician did not wash his hands before performing it; none used IPE; from 313 observed aspirations, on 249 the hands were not previously washed; from 176 introduced diets, on 141 times there was no interruption during aspiration; on 288 times not all IPEs were used; on less than half (156 times) the hands were washed after the procedure; the respiratory phyisiotherapy was performed 70 times and from those, on 45 the professionals did not previously wash their hands; 33 did not interrupt the diet. From the remaining 17, 13 were diagnosed with MVAP between 48 and 72 hours since the use of $M V$ and the data obtained on the structured observations point to the risk of these patients having MVAP.

KEYWORDS: Cross Infection; Nosocomial Pneumonia, Artificial Ventilation.

\footnotetext{
* Parte da Dissertação do Mestrado em Enfermagem UFRN

1 Enfermeira Intensivista, Mestra em Enfermagem UFRN. E-mail: izaurafreire@hotmail.com

Doutora em Enfermagem USP, Prof ${ }^{\mathrm{a}}$ Adjunta UFRN. E-mail: glaucea@digizap.com.br

${ }^{3}$ Enfermeira Clínica, Mestranda em Enfermagem UFRN. E-mail: cristianeramos@hotmail.com
} 
RESUMEN: Estudio descriptivo, prospectivo con abordaje cuantitativa em la urgencia y UTI, con el propósito de identificar los cuidados prestados por los profesionales y la asociación entre la VM y el aparecimiento de neumonía. La población fue de 68 profesionales. De los 38 enfermos entubados, 17 murieron y 4 sacados del tubo antes de completar 48 horas. Fueron hechos exámenes de secreción traqueal cuya etiología más frecuente ha sido el Pseudomonas aureus. Los cuidados realizados antes de la VM em los ventiladores mecánicos, circuitos respiratórios y productores de humedad, en 25 , no ha sido realizada la limpieza y desinfección, 21 fueron montados sin técnica de limpieza; en el momento de la instalación, el ventilador fue testado 26 veces com pulmón no estéril; el condensador presente en 87 veces, fue despreciado em 70; por 52 veces los profesionales no habian lavado las manos después; em 11 de las 17 intubaciones, el médico no habia lavado las manos; nádie habia

\section{INTRODUÇÃO}

Infecção Hospitalar (IH), institucional ou nosocomial, segundo o Ministério da Saúde (MS) é qualquer infecção adquirida após a internação do paciente e que se manifeste durante sua permanência no hospital ou mesmo após a alta, uma vez que possa ser relacionada com a hospitalização (BRASIL, 1998).

A ocorrência dessas infecções tem sido reconhecida como importante problema de saúde pública no Brasil e no mundo, e a principal causa de iatrogenia da pessoa institucionalizada submetida a intervenções curativas. As estatísticas internacionais de incidência mostravam na década de 80 taxas variáveis de 3,5 a $15,5 \%$, com letalidade entre $13 \%$ a $17 \%$, nos Estados Unidos, e uma prevalência de 9,2\% nessa mesma década no Reino Unido. Já nos países latino-americanos, essas taxas variavam de $5 \%$ a $70 \%$ (LACERDA, 2000).

É importante ressaltar que a maioria das $\mathrm{IH}$ manifesta-se como complicações naturais de pacientes gravemente enfermos, decorrentes de um desequilíbrio entre uma flora microbiana normal e seus mecanismos de defesa. Esse desequilíbrio é provocado por determinadas doenças responsáveis pela hospitalização e procedimentos invasivos ou imunossupressivos que o doente, correta ou incorretamente, foi submetido. No entanto, algumas infecções hospitalares são evitáveis, outras não. Essas infecções resultam de interações complexas e múltiplos fatores causais, que interagem diferentemente, predispondo a infecções de diversos tipos (FERNANDES; RIBEIRO FILHO; BARROSO, 2000). utilizado EPI; de las 313 aspiraciones, en 249 las manos no fueron lavadas; de las 176 dietas introducidas, en no ocorrió interrupción durante la aspiración; em 232 veces el suero fisiológico estaba despreciado; en menos de la mitad, las manos fueron lavadas después; la fisioterapia respiratória fue realizada 70 veces y en ese procedimiento, en 45 , los profesionales no realizaron la ablución de las manos; 33 no interrumpieron el régimen; prevaleció la alteración de decúbito en el horario de la mañana. Hemos concluído que de los 17 enfermos que participaron del estudio, 13 tuvieron dianóstico de PAVM entre 48 y después de 72 horas e utilización de la VM y los datos obtenidos en las observaciones estructuradas, señalan hacia um riesgo de que eses enfermos tengan PAVM.

PALABRAS CLAVE: Infección Hospitalaria; Neumonía Nosocomial, Ventilación Artificial.

As IH preveníveis, em geral, estão relacionadas ao uso de equipamentos e/ou procedimentos específicos, apresentando, em sua origem, algum evento possivelmente alterável. Logo, atribui-se a falhas nos cuidados dispensados ao paciente, sendo freqüentemente causadas por microorganismos adquiridos no hospital (CAVALCANTE et al, 2000).

Sabemos que os custos dessas infecções impõem um encarecimento do atendimento, na medida em que causa aumento da demanda terapêutica (gastos com antibiótico), da permanência hospitalar e da morbi-mortalidade. Esses custos são classificados pelo MS como: custos diretos, que estão intimamente relacionados às despesas do paciente com $\mathrm{IH}$; indiretos, que são resultantes da morbidade, como afastamento de trabalho, seqüela de alguma doença ou mesmo morte e os custos inatingíveis, impossíveis de serem medidos economicamente, pois compreendem os distúrbios provocados pela dor, mal-estar, isolamento, angústia e pelo sofrimento experimentado pelo paciente no ambiente hospitalar (SILVA, 2000, CAVALCANTI; HINRICHSEN, 2004).

A Pneumonia Nosocomial é definida como a "infecção do trato respiratório inferior que ocorre 48 horas ou mais após a internação no hospital, desde que não esteja presente ou em incubação na admissão hospitalar" (ROCHA, 2001, p.190). A Pneumonia Associada à Ventilação Mecânica (PAVM), objeto do nosso estudo, é uma forma de pneumonia hospitalar, sendo a infecção mais freqüente na Europa e a segunda nos hospitais americanos, estando relacionada a taxas de mortalidade de $30 \%$ a $60 \%$ dos pacientes hospitalizados (SADER et al, 2001). 


\section{ARTIGO ORIGINAL}

Na América Latina e no Brasil, os estudos a que tivemos acesso mostram que sua incidência, para cada 100 dias de ventilação mecânica, varia de 13 a $80 \%$ ou de 2,6 a 6,2, com mortalidade de 20 a 75\% (SILVA; OLIVEIRA, 2004).

PEREIRA et al. (1999, p.2) falando sobre o controle da $\mathrm{IH}$, dizem que para um "Programa de Controle de infecção hospitalar $(\mathrm{PCIH})$ tenha êxito, é essencial que haja participação ativa dos vários setores do hospital que lhes fornecem a infra-estrutura mínima necessária à sua efetiva implantação".

Portanto, conhecendo as causas que levam a esta afecção, identificamos que as medidas de prevenção em especial as pneumonias são essenciais, devendo ser implantadas estratégias de controle centrando suas ações na padronização e no treinamento de condutas para a assistência aos pacientes de risco. De maneira geral, o sucesso depende do envolvimento de toda a equipe de atendimento, sendo fundamental a educação contínua de todos os profissionais que trabalham com pacientes predispostos a esta síndrome.

Por essas considerações, entendemos que a profilaxia dessas infecções deve-se em grande parte à equipe que cuida do paciente, em especial a de enfermagem, que responde por vários mecanismos de prevenção, seja em atividades administrativas, de supervisão e de treinamento de pessoal, seja nos cuidados prestados aos pacientes admitidos nas unidades de urgência e UTI.

Diante dessa argumentação, não se pode fugir do compromisso social de procurar preservar o bemestar físico, mental e emocional do paciente, numa visão holística, buscando a excelência no atendimento, competência profissional e, conseqüentemente, minimizar a ocorrência de PAVM.

Partimos, então, do pressuposto de que a utilização por parte da equipe de enfermagem, médica e de fisioterapia dos passos das diretrizes para a prevenção das infecções nosocomiais pode prevenir a PAVM nestes pacientes com ventilação mecânica invasiva.

Baseando-nos nessas considerações, questionamos: qual a incidência da PAVM nas unidades de urgência e UTI? A equipe responsável pelos procedimentos dirigidos aos pacientes com VM segue as diretrizes para a prevenção das PAVM? Existe associação entre os cuidados realizados pela equipe em pacientes com VM e o aparecimento de pneumonia?

Preocupados com o alto índice de PAVM nestas unidades, resolvemos fazer este estudo com o objetivo de identificar os cuidados prestados pelos profissionais e a associação entre a VM e o aparecimento de pneumonia.
Consideramos esta pesquisa de suma importância no que se refere à prevenção da infecção hospitalar, que tantos danos financeiros e morais trazem ao paciente e ao Estado. É importante também, no sentido de que ao identificarmos como estes pacientes estão sendo cuidados podermos montar estratégias para melhorar a qualidade da assistência. Assim, esperamos que os resultados deste estudo possam subsidiar aqueles que trabalham junto a pacientes que necessitam utilizar a ventilação mecânica e com isso prevenir infecções respiratórias, principalmente as pneumonias que são muitas vezes decorrentes dessas terapêuticas.

\section{METODOLOGIA}

A pesquisa é de abordagem quantitativa do tipo exploratória e descritiva, realizada nas Unidades de Urgência e Terapia Intensiva do Pronto Socorro Clóvis Sarinho.

A população constou de 68 profissionais sendo 14 enfermeiros, 22 técnicos de enfermagem, 14 auxiliares de enfermagem, 11 médicos e 07 fisioterapeutas.

Para elaborarmos esse instrumento tomamos como base os fundamentos preconizados por vários autores, sendo o Guidelines for Prevention of Nosocomial Pneumonia (CDC, 1997) o principal. Tais procedimentos são iniciados com a intubação endotraqueal, incluindo os cuidados relacionados ao paciente, materiais e equipamentos utilizados para ventilação mecânica e condutas diagnósticas para confirmação dessa infecção. Consta também de dados de caracterização dos pacientes em VM e dos profissionais de saúde.

A coleta de dados foi realizada nos meses de janeiro e fevereiro de 2005, durante os três turnos, em pacientes com uso de VM sem história pregressa de infecções respiratórias anterior ao uso do respirador.

Após autorização pelo Comitê de Ética da Universidade Federal do Rio Grande do Norte fizemos o pré-teste do instrumento com $10 \%$ da população a ser estudada, para avaliar a sua aplicabilidade.

Os dados foram coletados nas 24 horas, ininterruptamente, com uma equipe composta de 07 alunas de iniciação científica do curso de graduação em Enfermagem da UFRN que se revezaram nos três turnos de trabalho treinados de maneira que todos falassem a mesma linguagem, evitando os vieses na pesquisa.

É importante ressaltar que ao iniciarmos a pesquisa, abordamos todos os profissionais da equipe de enfermagem, médica, nutrição e de fisioterapia em relação à pesquisa, quando solicitamos a leitura e assinatura do termo de livre consentimento para 
participar do estudo, de acordo com os princípios que regem a Resolução do Conselho Nacional de Saúde $\mathrm{n}^{0}$ 196/96 (BRASIL, 2000), cujo protocolo de registro é CEP-UFRN 101-04.

De posse do consentimento, passamos a observar os procedimentos realizados pelos profissionais. A observação foi concluída após o diagnóstico de pneumonia, extubação, transferência ou óbito. Todos estes dados foram registrados de acordo com sua ocorrência.

A técnica de coleta de dados utilizada foi a observação estruturada. Para completar os dados durante as observações, utilizamos também um diário de campo. (POLIT; BECK; HUNGLER, 2004).

\section{RESULTADOS E DISCUSSÃO}

Entre os 38 pacientes submetidos à VM, 25 $(65,79 \%)$ eram do sexo masculino, o mesmo acontecendo com os 17 pacientes que permaneceram na VM após 48 horas, com 14 (82,35\%).

Observamos que dos 17 pacientes que permaneceram em VM após as 48 horas, predominou a faixa etária de 55 a 64 anos (23,53\%), seguidas de 35 a 44 e 45 a 54 anos, ambas com o mesmo percentual (17,65\%), e uma idade média de 51,4 anos.

AGUILLERA \& ORTÍZ (1996), ao pesquisarem uma população na UTI sobre a incidência de pneumonia nosocomial, encontraram uma população mais jovem, com uma idade média de 44,2 anos.

No entanto, outros autores obtiveram idade que variavam entre 59 a 65 anos (ZEITOUN et al, 2001, TEIXEIRA et al, 2004).

Quanto ao grau de instrução dos 38 pacientes intubados, observamos, que os não alfabetizados representam um maior percentual $(36,36 \%)$, seguidos daqueles com ensino fundamental completo $(30,30 \%)$.

Os 17 pacientes que permaneceram em VM após 48 horas, a maior freqüência também foi dos não alfabetizados (35,29\%), seguidos do fundamental completo e fundamental incompleto, ambos com o mesmo percentual $(23,53 \%)$.

O Instituto Nacional de Estudos e pesquisas Educacionais Anísio Teixeira - INEP (2003), reforça que o país tem como marca básica as desigualdades sociais, não podendo ser diferente com 0 analfabetismo. Isso vem a corroborar os dados que obtivemos, uma vez que o nosso estudo foi realizado no Nordeste, e é de conhecimento de todos que esta região possui a maior taxa de não alfabetizados do país, com um contingente de quase oito milhões, correspondendo a $50 \%$ do total do país (BRASIL, 2003).
Em relação ao diagnóstico médico dos 38 pacientes submetidos à intubação, prevaleceu o AVC (28,85\%), seguido do TCE $(13,46 \%)$.

As estatísticas do MS, no Brasil, apontam essas doenças como as principais causas de mortalidade com $32 \%$, em todas as regiões, seguidas pelas causas externas (15\%), neoplasias (15\%) e doenças do aparelho respiratório (11\%). A mesma fonte de dados justifica este fato ao perfil de mortalidade da população brasileira que tem passado por transformações, destacando-se a queda dos óbitos infantis, a redução relativa de óbitos por doenças infecciosas e o aumento das mortes por doenças crônico-degenerativas (BRASIL, 2001).

Salientamos o percentual expressivo dos pacientes acometidos de TCE $(13,46 \%)$ na nossa pesquisa, que segundo ROGERS, OSBORN, POUSADA (1992); PAVELQUEIRES (1997) é um tipo de evento é responsável por aproximadamente um quarto das mortes por trauma.

Em relação aos 38 pacientes submetidos à intubação endotraqueal, 21 (55,26\%) deixaram de fazer uso do ventilador mecânico antes das 48 horas; acrescentamos que, desse total, $04(19,05 \%)$ foram extubados e 17 (80,85\%) evoluíram para óbito. Portanto, não foi possível fazer o diagnóstico de PAVM.

Quanto às mortes ocorridas, tanto o diagnóstico médico como a gravidade dos casos atendidos nos setores em estudo favoreceram à perda desses pacientes nas primeiras horas ou dias após o evento. Enfatizamos que o diagnóstico médico mais freqüente dos pacientes que evoluíram para óbito antes de completar 48 horas de estudo também foi o AVC $(28,57 \%)$.

No que se refere a extubação, grande número de pacientes com doenças cardiorespiratórias, neurológicas, entre tantas outras, são admitidos com dificuldade ventilatória intensa ou diminuição da saturação de oxigênio no sangue arterial $\left(\mathrm{SaO}_{2}\right)$, sendo necessário a intubação ou traqueostomia com conseqüente uso de ventilador mecânico. Quando a evolução do paciente é favorável, como foi o caso no nosso estudo, em um determinado momento é procedida a extubação (GOLDWASSER et al, 2000).

Ainda em relação a essa análise, 17 (44,74\%) pacientes permaneceram em VM após 48 horas. Porém, dos 17 que permaneceram em VM, 13 $(76,47 \%)$ tiveram o diagnóstico de PAVM confirmado, sendo que $04(30,77 \%)$ entre 48 a 72 horas e 09 $(69,23 \%)$ após 72 horas.

No nosso estudo, o diagnóstico de PAVM foi confirmado com as seguintes abordagens: 10 (76,92\%) realizaram cultura de secreção traqueal, sendo 02 $(20,00 \%)$ culturas antes de 72 horas e $08(80,00 \%)$ após esse tempo. Os agentes etiológicos encontrados 


\section{ARTIGO ORIGINAL}

antes de 72 horas foram Klebsiella sp $01(10,00 \%)$ e Streptococcus pneumonias $01(10,00 \%)$. E após 72 horas Klebsiella sp 02 (20,00\%), Pseudomonas aeruginosa $03(30,00 \%)$, Staphilococcus aureus 02 $(20,00 \%)$, e Staphylococcus aureus + Pseudomonas aeruginosa $01(10,00) ; 03(23,08 \%)$ pacientes tiveram diagnósticos confirmados através de sintomas clínicos e radiológicos, sendo 02 antes de 72 horas e 01 após esse período. Os agentes etiológicos predominantes nas duas etapas foram o Pseudomonas aeruginosa e Klebsiella sp, presentes, cada agente, em $4(36,36 \%)$ culturas.

Os dados encontrados se assemelham aos da literatura pesquisada, quando afirmam que as PAVM que se desenvolvem dentro de até 72 horas após a intubação endotraqueal são geralmente causadas por microorganismos de baixa resistência, destacando-se o Streptococcus pneumoniae, Haemophilus influenzae e Staphilococcus aureus oxacilina sensível. Após este período, os casos relacionam-se a microorganismos resistentes, principalmente o Staphilococcus aureus oxacilina resistente, as enterobactérias e os bacilos gram negativos não fermentadores, destacando-se o Pseudomonas aeruginosa e o Acinetobacter spp (CARDOSO, 2001; ANVISA, 2000; SILVA, NOGUEIRA, PEIXOTO, 2003).

Identificamos que $16(94,12 \%)$ dos pacientes utilizaram os bloqueadores $\mathrm{H}_{2}$. Somente $01(5,88 \%)$ não fez uso de qualquer medicamento.O uso dos fármacos na profilaxia da lesão aguda da mucosa gástrica mostram que os bloqueadores $\mathrm{H}_{2}$, apesar de diminuírem significativamente essa incidência em até $50 \%$, leva a uma alcalinização do estômago aumentando a colonização bacteriana da mucosa gástrica, e, conseqüentemente, a pneumonia nosocomial. O sucralfato parece ser tão efetivo como os bloqueadores $\mathrm{H}_{2}$, e associa-se a uma menor incidência de pneumonia nosocomial (AGUILLERA \& ORTíZ, 1996; CDC, 1997; TRYBA, 1991; FERNANDES, ZAMORANO, TOREZAN FILHO, 2000; HERNANDES et al, 2001; RODRÍGUEZ et al, 2002). 
Quadro 01 - Distribuição dos profissionais do setor de urgência e UTI, segundo categoria profissional, sexo, idade, tempo de serviço e unidade de trabalho - PSCS - Natal/RN, 2005.

\begin{tabular}{|c|c|c|}
\hline Categoria Profissional & $\mathbf{N}$ & $\%$ \\
\hline Enfermeiro & 14 & 20,59 \\
\hline Tec. de Enfermagem & 22 & 32,35 \\
\hline Aux. de Enfermagem & 14 & 20,59 \\
\hline Médico & 11 & 10,29 \\
\hline Fisioterapeuta & 07 & 16,18 \\
\hline Total & 68 & 100,00 \\
\hline \multicolumn{3}{|l|}{ Sexo } \\
\hline Masculino & 21 & 30,88 \\
\hline Feminino & 47 & 69,12 \\
\hline Total & 68 & 100,00 \\
\hline \multicolumn{3}{|l|}{ Grau de instrução } \\
\hline Nível médio & 35 & 51,47 \\
\hline Nível superior & 33 & 48,53 \\
\hline Total & 68 & 100,00 \\
\hline \multicolumn{3}{|l|}{ Idade (anos) } \\
\hline $20|-| 30$ & 09 & 13,24 \\
\hline $30 \mid-40$ & 27 & 39,71 \\
\hline $40 \mid-150$ & 30 & 44,12 \\
\hline $50|-| 60$ & 02 & 02,94 \\
\hline Total & 68 & 100,00 \\
\hline \multicolumn{3}{|l|}{ Tempo de serviço (anos) } \\
\hline$<1$ & 05 & 07,35 \\
\hline $01|-| 04$ & 10 & 14,71 \\
\hline $05|-| 09$ & 22 & 32,35 \\
\hline $10 \mid-14$ & 11 & 16,18 \\
\hline $15 \mid-20$ & 18 & 26,47 \\
\hline$>20$ & 02 & 02,94 \\
\hline Total & 68 & 100,00 \\
\hline \multicolumn{3}{|l|}{ Unidade de trabalho } \\
\hline UTI & 48 & 70,59 \\
\hline Setor de urgência & 20 & 29,41 \\
\hline Total & 68 & 100,00 \\
\hline
\end{tabular}


Observamos no Quadro 01 que dos 68 profissionais que trabalham nas unidades em estudo, os técnicos e auxiliares de enfermagem, juntos, constituem a principal categoria, por representar 52,94.

Esses dados reforçam a realidade do nosso País, onde os auxiliares e técnicos de enfermagem continuam sendo a maioria no quadro de pessoal dos hospitais. As razões que contribuíram para esse fato são a existência do grande número de escolas formadoras, a ênfase dada pelo governo federal aos cursos profissionalizantes e a faixa salarial, menor do que a dos profissionais de nível superior, daí o maior número de contratações dessa categoria (ALMEIDA et al, 1997; BEZERRA, 2000; MOURA, 2004; RIBEIRO \& PEDRÃO, 2005; COFEN, 2005).

O sexo feminino predominou nas três categorias estudadas com $47(69,12 \%)$ do total de profissionais. A enfermagem e fisioterapia eram compostas principalmente por mulheres com $74,51 \%$ e $85,71 \%$ respectivamente. No entanto, a categoria médica era formada mais por homens com $63,64 \%$ desse sexo.
Segundo ALMEIDA et al (1997); COFEN (2005), a equipe de enfermagem em quase a sua totalidade é composta por mulheres. Esses dados contribuem com os nossos achados, uma vez que a equipe de enfermagem teve uma grande representatividade no estudo.

O grau de instrução predominante foi o ensino médio, com $51,47 \%$, e esse fato se justifica pelo percentual significante de auxiliares e técnicos de enfermagem, uma vez que este é um dos requisitos para obtenção deste título (RIBEIRO \& PEDRÃO, 2005; COFEN, 2005).

No que se refere ao tempo de serviço, os dados de BEZERRA (2000); NICOLETE (2001) e MOURA (2004) se assemelham àqueles da nossa pesquisa, predominando o tempo de 5 a 9 anos (32,35\%) seguido de 14 a 20 anos (26,47\%).

Quanto à unidade onde desenvolviam as suas atividades, $48(70,59 \%)$ trabalhavam na UTI e 20 $(29,41 \%)$ no setor de urgência.

Quadro 02 - Distribuição segundo os cuidados realizados com os ventiladores mecânicos antes do uso, no momento da instalação e durante o uso. PSCS - Natal/RN, 2005.

\begin{tabular}{|c|c|c|c|c|c|c|}
\hline \multirow{2}{*}{ Ventilador Mecânico Antes do uso } & \multicolumn{2}{|c|}{ SIM } & \multicolumn{2}{|c|}{ NÃO } & \multicolumn{2}{|c|}{ TOTAL } \\
\hline & $\mathbf{N}$ & $\%$ & $\mathbf{N}$ & $\%$ & $\mathbf{N}$ & $\%$ \\
\hline Realiza limpeza e desinfecção do ventilador antes da montagem & 10 & 28,57 & 25 & 71,43 & 35 & 100,00 \\
\hline Monta o ventilador mecânico com técnica asséptica & 14 & 40,00 & 21 & 60,00 & 35 & 100,00 \\
\hline Testa o ventilador mecânico com pulmão estéril & 02 & 06,89 & 27 & 93,11 & $29^{*}$ & 100,00 \\
\hline Protege a conexão em Y do circuito com material estéril & 08 & 22,85 & 27 & 77,15 & 35 & 100,00 \\
\hline Coloca o rótulo da data e assinatura de quem montou & 17 & 48,57 & 18 & 51,43 & 35 & 100,00 \\
\hline Deixa o umidificador vazio & 30 & 85,71 & 05 & 14,29 & 35 & 100,00 \\
\hline \multirow{2}{*}{ No momento da instalação } & \multicolumn{2}{|c|}{ SIM } & \multicolumn{2}{|c|}{ NÃO } & \multicolumn{2}{|c|}{ TOTAL } \\
\hline & $\mathbf{N}$ & $\%$ & $\mathbf{N}$ & $\%$ & $\mathbf{N}$ & $\%$ \\
\hline Testa o ventilador mecânico com pulmão estéril & 03 & 13,00 & 26 & 87,00 & $29^{*}$ & 100,00 \\
\hline Usa água estéril nos umidificadores & 23 & 65,72 & 12 & 34,28 & 35 & 100,00 \\
\hline Coloca água no umidificador somente ao iniciar a VM & 30 & 85,71 & 05 & 14,29 & 35 & 100,00 \\
\hline \multirow{2}{*}{ Durante a VM } & \multicolumn{2}{|c|}{ SIM } & \multicolumn{2}{|c|}{ NÃO } & \multicolumn{2}{|c|}{ TOTAL } \\
\hline & $\mathbf{N}$ & $\%$ & $\mathbf{N}$ & $\%$ & $\mathbf{N}$ & $\%$ \\
\hline Descarta o condensado que se forma no circuito & 70 & 80,45 & 17 & 19,55 & $87^{\star \star}$ & 100,00 \\
\hline Lava as mãos após o procedimento & 18 & 25,72 & 52 & 74,28 & $70^{\star \star \star}$ & 100,00 \\
\hline Usa água estéril nos umidificadores & 58 & 84,05 & 11 & 15,95 & $69 * * * *$ & 100,00 \\
\hline $\begin{array}{l}\text { Despreza o líquido remanescente dos umidificadores antes de } \\
\text { colocar água }\end{array}$ & 00 & 00,00 & 69 & 100,00 & 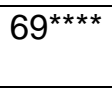 & 100,00 \\
\hline Realiza troca do circuito ventilatório & 00 & 00,00 & 35 & 100,00 & 35 & 100,00 \\
\hline
\end{tabular}

* 06 ventiladores mecânicos não foram testados antes e após a montagem

** 26 Não apresentaram condensados

*** Em 17 vezes o condensado não foi descartado

**** 44 permaneceram com a água sem serem completadas 
O Quadro 02 mostra que a limpeza e desinfecção dos ventiladores antes da montagem não foi realizado em 25 momentos (71,43\%). Das 10 vezes que esse cuidado foi executado 09 (90\%) a auxiliar de serviços gerais da UTI foi quem realizou e apenas $01(10 \%)$ a auxiliar de enfermagem do setor de urgência fez a limpeza e desinfecção desse aparelho.

Os dados encontrados contradizem as orientações de PASSOS et al (2000) quando afirmam que os ventiladores devem sofrer limpeza diária com água e sabão ou fricção com álcool a $70 \%$ por 30 segundos ou de acordo com a orientação do fabricante.

Em relação ao uso da técnica asséptica na montagem, das 35 vezes que esse procedimento aconteceu, em 21 (60\%) o material foi contaminado, não havendo lavagem das mãos, uso de luvas estéreis e demais cuidados para não contaminar os componentes dos ventiladores.

Quanto ao pulmão de teste estar desinfectado ou estéril, registramos que das 35 vezes que foi usado, somente em 29 (82,86\%) foram testados e que destes $27(93,11 \%)$ o pulmão utilizado estava guardado (antes de ser usado) em saco não estéril ou desprotegido, não havendo a preocupação de esterilizá-los ou desinfetálos após cada uso.

Vemos também que do total de vezes que os ventiladores foram montados (35), em 27 (77,15\%) os profissionais utilizaram luvas de procedimentos ou sacos coletores não estéreis para proteger a conecção em $Y$ (parte que deverá conectar-se ao TOT ou traqueóstomo) do circuito respiratório. Com a finalidade de observar a data de montagem e o período de validade para uso de cada material estéril, é norma da instituição a colocação de rótulo com data e assinatura do responsável. Detectamos, porém, que em 18 $(51,43 \%)$ desses procedimentos essa norma não foi respeitada. A não observância dessas diretrizes favorece a utilização de material com data de validade vencida e conseqüentemente aumenta o risco de infecção.

Quando observamos quem montou o ventilador mecânico, vimos que $26(74,29 \%)$ foi por enfermeiros e $09(25,71 \%)$ foi por auxiliar de enfermagem.

Dos 29 ventiladores testados, em 26 vezes $(87,00 \%)$ não foi feito uso do pulmão estéril ou desinfectado; 23 vezes $(65,72 \%)$ utilizaram água estéril para encher os umidificadores e em 30 vezes (85,71\%) a água foi posta somente no momento da instalação do ventilador.

Observamos também como se dava o cuidado em relação ao ventilador mecânico durante o período em que o paciente estava sendo submetido à VM. Nesse sentido o circuito do ventilador era observado nos três turnos (manhã, tarde e noite), quanto à presença ou não de condensado. Das 113 vezes que fizemos essa conferência, em 26 delas não havia presença de condensado, das outras 87 vezes restantes, ressaltamos que em $70 \quad(80,45 \%) \quad$ o condensado foi descartado. Detectamos, também, que $17(19,55 \%)$ vezes os tubos corrugados encontravamse com grande quantidade de líquido condensado, não havendo preocupação por parte do profissional em retirá-lo. No que se refere à lavagem das mãos após, essa ação vimos que das 70 vezes em que o condensado foi descartado, em 52 procedimentos $(74,28 \%)$ essa conduta não foi realizada.

Com relação à condensação, PASSOS et al, (2000) ressaltam que a água condensada nos circuitos deve ser esvaziada sempre que necessário, porque, além de aumentar a resistência, aumenta a pressão positiva ao final da expiração (PEEP) e o risco de contaminação. Nas diretrizes de prevenção da pneumonia nosocomial elaboradas pelo CDC (1997) e ANVISA (2000), além de ser enfatizado que o condensado deve ser periodicamente descartado, ainda salientam a necessidade de lavar as mãos após esse procedimento, com a finalidade de diminuir as infecções cruzadas.

Durante a VM, observamos se era colocada água estéril no umidificador do ventilador já em uso e se esse líquido era trocado ou completado. Em 69 vezes que foi colocado água, 58 (84,05\%) ela estava estéril. Já em relação à troca da água, essa prática não é realizada nos setores em estudo, isto é, o conteúdo era mantido no umidificador ao longo da permanência do paciente no ventilador mecânico. Observamos, no entanto, que quando o umidificador estava vazio ou com pouco líquido, em $100 \%$ das vezes foi feito apenas a complementação.

Contradizendo os dados obtidos, PASSOS et al (2000), ANVISA (2000) e CDC (1987) afirmam que os umidificadores que usam água, essa deve está estéril, devendo ser trocada diariamente e sempre que for preciso para manter o nível adequado. É importante ressaltar que o nível da água não deve ser completado e sim completamente substituído.

Quanto ao tempo de troca dos circuitos dos ventiladores mecânicos dos setores em estudo, não existia um intervalo pré-fixado. No entanto, esse procedimento não foi realizado nenhuma vez no período da pesquisa.

A ANVISA (2000) afirma que os circuitos respiratórios não devem ser trocados em intervalos inferiores a 48 horas. Ainda não existe definição para tempo de troca. Entretanto, ela recomenda que seja feita a cada sete dias. 
ARTIGO ORIGINAL

Quadro 03 - Distribuição dos passos do procedimento de intubação endotraqueal nos 17 pacientes e o risco de PAVM. PSCS - Natal/RN, 2005.

\begin{tabular}{|c|c|c|c|c|c|c|c|}
\hline \multirow{2}{*}{\multicolumn{2}{|c|}{ PASSOS DO PROCEDIMENTO }} & \multicolumn{4}{|c|}{ DIAGNÓSTICO DE PNEUMONIA } & \multirow{2}{*}{\multicolumn{2}{|c|}{ TOTAL }} \\
\hline & & \multicolumn{2}{|c|}{ NÃO } & \multicolumn{2}{|c|}{ SIM } & & \\
\hline & & $\mathbf{N}$ & $\%$ & $\mathbf{N}$ & $\%$ & $\mathbf{N}$ & $\%$ \\
\hline \multirow{3}{*}{ Armazena o material para intubação } & SIM & 04 & 23,53 & 13 & 76,47 & 17 & 100,00 \\
\hline & NÃO & 00 & 00,00 & 00 & 00,00 & 00 & 00,00 \\
\hline & TOTAL & 04 & 23,53 & 13 & 76,47 & 17 & 100,00 \\
\hline \multirow{3}{*}{ Mantém o material no prazo de validade } & SIM & 04 & 23,53 & 13 & 76,47 & 17 & 100,00 \\
\hline & NÃO & 00 & 00,00 & 00 & 00,00 & 00 & 00,00 \\
\hline & TOTAL & 04 & 23,53 & 13 & 76,47 & 17 & 100,00 \\
\hline \multirow{3}{*}{ Lava as mãos antes da intubação } & $\operatorname{SIM}$ & 02 & 11,76 & 04 & 23,53 & 06 & 35,29 \\
\hline & NÃO & 02 & 11,76 & 09 & 52,94 & 11 & 64,71 \\
\hline & TOTAL & 04 & 23,53 & 13 & 76,47 & 17 & 100,00 \\
\hline \multirow{3}{*}{ Usa EPIs } & SIM & 00 & 00,00 & 00 & 00,00 & 00 & 00,00 \\
\hline & NÃO & 04 & 23,53 & 13 & 76,47 & 17 & 100,00 \\
\hline & TOTAL & 04 & 23,53 & 13 & 76,47 & 17 & 100,00 \\
\hline \multirow{3}{*}{ Usa luvas estéreis } & SIM & 03 & 17,65 & 13 & 76,47 & 16 & 94,12 \\
\hline & NÃO & 01 & 05,88 & 00 & 00,00 & 01 & 05,88 \\
\hline & TOTAL & 04 & 23,53 & 13 & 76,47 & 17 & 100,00 \\
\hline \multirow{3}{*}{ Testa o cuff com seringa estéril } & $\operatorname{SIM}$ & 04 & 23,53 & 13 & 76,47 & 17 & 100,00 \\
\hline & NÃO & 00 & 00,00 & 00 & 00,00 & 00 & 00,00 \\
\hline & TOTAL & 04 & 23,53 & 13 & 76,47 & 17 & 100,00 \\
\hline \multirow{3}{*}{ Utiliza fio guia estéril } & SIM & 02 & 13,33 & 09 & 60,00 & 11 & 73,33 \\
\hline & NÃO & 01 & 06,67 & 03 & 20,00 & 04 & 26,67 \\
\hline & TOTAL & 03 & 20,00 & 12 & 80,00 & 15 & 100,00 \\
\hline \multirow{3}{*}{ Introduz o TOT sem intercorrências } & SIM & 03 & 17,65 & 06 & 35,29 & 09 & 52,94 \\
\hline & NÃO & 01 & 05,88 & 07 & 41,18 & 08 & 47,06 \\
\hline & TOTAL & 04 & 23,53 & 13 & 76,47 & 17 & 100,00 \\
\hline \multirow{3}{*}{ Descarta o TOT após tentativas sem êxito } & SIM & 00 & 00,00 & 02 & 25,00 & 02 & 25,00 \\
\hline & NÃO & 01 & 12,50 & 05 & 62,50 & 06 & 75,00 \\
\hline & TOTAL & 01 & 12,50 & 07 & 87,50 & 08 & 100,00 \\
\hline \multirow{3}{*}{ Troca de luvas quando as contamina } & SIM & 00 & 00,00 & 01 & 07,69 & 01 & 07,69 \\
\hline & NÃO & 03 & 23,08 & 09 & 69,23 & 12 & 92,31 \\
\hline & TOTAL & 03 & 23,08 & 10 & 76,92 & 13 & 100,00 \\
\hline \multirow{3}{*}{ Infla o cuff com seringa estéril } & SIM & 04 & 23,53 & 13 & 76,47 & 13 & 100,00 \\
\hline & NÃO & 00 & 00,00 & 00 & 00,00 & 00 & 00,00 \\
\hline & TOTAL & 04 & 23,53 & 13 & 76,47 & 17 & 100,00 \\
\hline \multirow{3}{*}{ Lava as mãos após a intubação } & $\operatorname{SIM}$ & 02 & 11,76 & 10 & 58,82 & 12 & 70,59 \\
\hline & NÃO & 02 & 11,76 & 03 & 17,65 & 05 & 29,41 \\
\hline & TOTAL & 04 & 23,53 & 13 & 76,47 & 17 & 100,00 \\
\hline
\end{tabular}

Como podemos observar no Quadro 03, o dado referente à condição de armazenamento do material de intubação como cânulas, seringas, luvas e xylocaina geléia (se estava ou não adequada), detectamos que $100 \%$ estava armazenado em condições adequadas, o mesmo acontecendo com relação ao prazo de validade.
No que se refere às condições ideais de armazenamento dos artigos médicos hospitalares de urgência, é recomendado que seja em ambiente limpo, organizados em carrinhos de urgência, de fácil manuseio e visualização, revisado e reposto diariamente para melhor controle dos lotes (SAMPAIO; FARIA, 1998). 
Quanto ao prazo de validade de materiais descartáveis, esse dado deve estar contido na embalagem do produto. Em relação aos materiais reesterilizáveis, este prazo deve ser estabelecido de acordo com o método de esterilização empregado, características do invólucro método de secagem das embalagens, número e condição de manipulação dos pacotes antes do uso e das condições de armazenamento (BRASIL, 2001).

Ressaltamos que dos 17 pacientes intubados, em $11(64,71 \%)$ os profissionais não lavaram as mãos antes desse procedimento. Quando analisamos separadamente aqueles pacientes que tiveram ou não pneumonia, observamos que em 09 (52,94\%) esse diagnóstico foi confirmado.

No estudo de PEREIRA et al (1999) sobre a adoção das medidas de precauções padrão executadas por anestesistas, foram encontrados dados semelhantes quando observaram que somente $9,5 \%$ destes profissionais lavavam as mãos antes das intubações.

SANTOS (2004) afirma que a lavagem das mãos é considerada a ação isolada mais importante no controle de infecções em serviços de saúde. Porém, a falta de adesão dos profissionais a esta prática é uma realidade em diversas partes do mundo, elevando a infecção hospitalar a números assustadores.

Inúmeras publicações científicas estão de acordo com estes dados e demonstram a correlação entre a lavagem das mãos e a redução na transmissão de infecções. A maioria absoluta dos especialistas em controle de infecção concorda que essa medida é o meio mais simples e eficaz de prevenir a transmissão de microorganismos no ambiente assistencial (CDC, 1997; ANVISA, 2000; PASSOS et al, 2000; SANTOS, 2004).

Quando observamos se os médicos usavam todos os Equipamentos de Proteção Individual (EPI) necessários para realizar a intubação (luvas, máscaras, óculos de proteção e aventais), vimos que 100\% dos profissionais não os utilizaram. Mas, quando analisamos os EPIs separadamente, detectamos que todos utilizaram luvas; 09 (52,94\%) fizeram uso de máscaras; nenhum utilizou óculos de proteção e somente $01(5,88 \%)$ utilizou avental.

GOMES (2003) afirma que as luvas devem ser usadas para tocar sangue, fluidos corpóreos, secreções e excreções, objetos contaminados, mucosas e pele não íntegra. As máscaras e óculos servem para proteger as mucosas quando houver riscos de respingos e o avental para prevenir a contaminação das roupas e proteger a pele de sangue, fluidos corpóreos, secreções e excreções. Esses EPIs também devem ser usados para diminuir a transmissão de um paciente ou fonte para outro paciente.
Em relação ao uso do capote, $14,3 \%$ dos anestesiologistas o vestiu para as punções espinhais, $4,8 \%$ para as entubações endotraqueais e $3,2 \%$ para a punções venosas. Já os óculos protetores não foram utilizados por nenhum dos profissionais observados (PEREIRA et al, 1999).

BEZERRA \& PEREIRA (2004), em pesquisa realizada numa unidade de clínica cirúrgica, detectaram que a maioria dos profissionais $(54,00 \%)$ não fizeram uso de EPIs ao prestarem assistência ao paciente.

Foi utilizado luvas estéreis para intubar 16 $(94,12 \%)$ dos pacientes, $13(76,47 \%)$ tiveram PAVM.

GONZÁLEZ et al (2004) afirmam que esse procedimento é necessário para evitar a contaminação da árvore traqueobrônquica e conseqüentemente o risco de infecção.

Prosseguindo a técnica desse procedimento, o médico antes de introduzir o tubo deverá testar o cuff com seringa estéril. Vimos que nesse estudo esse procedimento foi realizado em $100 \%$ das intubações.

Segundo PEIXOTO \& GEOCONDA (1998) o cuff deverá ser testado com seringa estéril utilizando 05 a $10 \mathrm{ml}$ de ar. A importância atribuída à testagem se dá ao fato de que, se o mesmo apresentar algum defeito, o paciente não tenha que ser reintubado e, no caso da seringa estéril, previne a introdução de microorganismos.

O fio guia foi usado em 15 intubações. Desse total em 11 (73,33\%) estava estéril. Ressaltamos que apesar do passo utilizado estar de acordo com as diretrizes preconizadas, 09 (60,00\%) tiveram PAVM.

Dos 17 pacientes estudados, em 8 houve a tentativa de introdução do TOT, e foi sem êxito. Porém, desses 06 (75\%) o tubo continuou sendo utilizado, mesmo após ter sido contaminado. Dos 08 pacientes, $05(62,50 \%)$ tiveram PAVM. Mais uma vez fica comprovada nesse estudo a vulnerabilidade que estão expostos esses pacientes ao serem submetidos a procedimentos invasivos.

Em referência ao cuff ser inflado com seringa estéril após a introdução do TOT, observamos que em $100 \%$ dos procedimentos foi feita de maneira adequada.

Quanto à lavagem das mãos após a intubação, esse fato ocorreu 12 vezes $(70,59 \%)$ das 17 procedimentos realizados. Como já foi dito em outros momentos da análise, essa técnica tem a finalidade de evitar contaminações de materiais, infecções cruzadas ou autocontaminação (CDC, 1997; ANVISA, 2000; OLIVEIRA \& ARMOND, 2001; SANTOS, 2004).

Os procedimentos a seguir não levam diretamente a riscos de infecção, porém podem causar complicações graves se não forem seguidos adequadamente. 
No que se refere ao Calibre do TOT, vimos que nas 17 intubações foi utilizado o TOT com calibre adequado, isto é, estavam entre 7,5 a $8,0 \mathrm{~mm}$ para mulheres e 8,0 a $9,0 \mathrm{~mm}$ para homens. A seleção do tamanho correto é fundamental, pois, quando pequenos, há um vazamento de ar entre a traquéia e o tubo, e, quando superiores à necessidade, podem lesar a traquéia e as cordas vocais (SAMPAIO; FARIA, 1998).

Em relação à lubrificação da cânula com xylocaína geléia antes da intubação, observamos que este fato ocorreu em 11 (64,71\%) das intubações realizadas.

Sobre essa técnica PEIXOTO \& GEOCONDA (1998) recomendam que a cânula deverá ser lubrificada com xylocaína geléia para facilitar sua inserção e minimizar o trauma na mucosa, acarretando lesões que servirão de porta de entrada à contaminação das vias aéreas.

A ausculta pulmonar foi realizada em $70,29 \%$ dos pacientes, enquanto a radiografia torácica não foi realizada em nenhum paciente logo após a intubação.

OLIVEIRA et al (2000) enfatizam a necessidade de avaliar a localização e altura do tubo e esta deve basear-se, inicialmente, em aspectos clínicos como: visibilização da passagem do tubo entre as cordas vocais, ausculta de ruídos respiratórios, ausência de ruídos ventilatórios no epigástrico, movimento simétrico do tórax durante a ventilação, melhora da hipoxemia, presença de condensação de ar no tubo durante a expiração.

No Segundo Consenso Brasileiro de Ventilação Mecânica, PASSOS et al (2000) atribuem à enfermagem os cuidados de verificação da pressão do cuff, no mínimo a cada 12 horas, fazendo a insuflação de volume, se necessário, para evitar escape de ar entre o tubo e a traquéia e movimentação.

No que diz respeito à informação prévia ao paciente sobre o procedimento a ser realizado, 100\% dos profissionais deixaram de fazê-lo. $O$ fato de o paciente encontrar-se com nível de consciência alterado (coma ou sedado) e o profissional julgar, muitas vezes, o procedimento desnecessário, pode levar a não valorização deste dado, considerado de grande importância na comunicação com a equipe de saúde (ZINN; SILVA, 2003). 
ARTIGO ORIGINAL

Quadro 04 - Distribuição dos passos do procedimento da aspiração das VAS e o risco de PAVM. PSCS - Natal/RN, 2005.

\begin{tabular}{|c|c|c|c|c|c|c|c|}
\hline \multirow{3}{*}{ PASSOS DO PROCEDIMENTO } & & \multicolumn{4}{|c|}{$\begin{array}{l}\text { DIAGNÓSTICO } \\
\text { PNEUMONIA }\end{array}$} & \multirow{2}{*}{\multicolumn{2}{|c|}{ TOTAL }} \\
\hline & & \multicolumn{2}{|c|}{ NÃO } & \multicolumn{2}{|c|}{ SIM } & & \\
\hline & & $\mathbf{N}$ & $\%$ & $\mathbf{N}$ & $\%$ & $\mathbf{N}$ & $\%$ \\
\hline \multirow{3}{*}{ Lava as mãos antes do procedimento } & SIM & 06 & 01,92 & 58 & 18,53 & 64 & 20,45 \\
\hline & NÃO & 22 & 07,03 & 227 & 72,52 & 249 & 79,55 \\
\hline & TOTAL & 28 & 08,95 & 285 & 91,05 & 313 & 100,00 \\
\hline \multirow{3}{*}{ Interrompe a dieta enteral } & $\mathrm{SIM}$ & 04 & 02,27 & 31 & 17,61 & 35 & 19,89 \\
\hline & NÃO & 07 & 03,98 & 134 & 76,14 & 141 & 80,11 \\
\hline & TOTAL & 11 & 06,25 & 165 & 93,75 & $176^{\star}$ & 100,00 \\
\hline \multirow{3}{*}{ Usa EPIs } & SIM & 04 & 01,28 & 21 & 06,71 & 25 & 07,99 \\
\hline & NÃO & 24 & 07,67 & 264 & 84,35 & 288 & 92,01 \\
\hline & TOTAL & 28 & 08,95 & 285 & 91,05 & 313 & 100,00 \\
\hline \multirow{3}{*}{ Usa luvas estéreis } & SIM & 25 & 07,99 & 273 & 87,22 & 298 & 95,21 \\
\hline & NÃO & 03 & 00,96 & 12 & 03,83 & 15 & 04,79 \\
\hline & TOTAL & 28 & 08,95 & 285 & 91,05 & 313 & 100,00 \\
\hline \multirow{3}{*}{ Usa cateter de aspiração estéril } & $\operatorname{SIM}$ & 28 & 08,95 & 281 & 89,78 & 309 & 98,72 \\
\hline & NÃO & 00 & 00,00 & 04 & 01,28 & 04 & 01,28 \\
\hline & TOTAL & 28 & 08,95 & 285 & 91,05 & 313 & 100,00 \\
\hline \multirow{3}{*}{ Segue a seqüência tubo, nariz e boca } & SIM & 24 & 07,67 & 242 & 77,32 & 266 & 84,98 \\
\hline & NÃO & 04 & 01,28 & 43 & 13,74 & 47 & 15,02 \\
\hline & TOTAL & 28 & 08,95 & 285 & 91,05 & 313 & 100,00 \\
\hline \multirow{3}{*}{ Usa gaze estéril para limpar secreções do cateter } & $\begin{array}{l}\text { SIM } \\
\text { NĨOO }\end{array}$ & \begin{tabular}{|l|}
10 \\
04
\end{tabular} & $\begin{array}{l}04,61 \\
01,84\end{array}$ & \begin{tabular}{|l|}
181 \\
22
\end{tabular} & $\begin{array}{l}83,41 \\
10,14\end{array}$ & \begin{tabular}{|l|}
191 \\
26
\end{tabular} & $\begin{array}{l}88,02 \\
11,98\end{array}$ \\
\hline & & & & & & $217^{*}$ & \\
\hline & TOTAL & 14 & 04,47 & 203 & 93,55 & * & 100,00 \\
\hline \multirow{3}{*}{ Fluidifica as secreções com SF estéril } & SIM & 16 & 06,13 & & 82,76 & 232 & 88,89 \\
\hline & NÃO & 07 & 02,68 & 22 & 08,43 & 29 & 11,11 \\
\hline & TOTAL & 23 & 08,81 & 238 & 91,18 & $\begin{array}{l}261^{*} \\
\star *\end{array}$ & 100,00 \\
\hline \multirow{3}{*}{ Utiliza ambu estéril } & SIM & 07 & 07,69 & 60 & 65,93 & 67 & 73,63 \\
\hline & NÃO & 00 & 00,00 & 24 & 26,37 & 24 & 26,37 \\
\hline & TOTAL & 07 & 07,69 & 84 & 92,31 & $\begin{array}{l}91^{\star *} \\
\star \star\end{array}$ & 100,00 \\
\hline \multirow{3}{*}{ Descarta o cateter após seqüência de aspiração } & SIM & 26 & 08,31 & 267 & 85,30 & 293 & 93,61 \\
\hline & NÃO & 02 & 00,64 & 18 & 05,75 & 20 & 06,39 \\
\hline & TOTAL & 28 & 08,95 & 285 & 91,05 & 313 & 100,00 \\
\hline \multirow{3}{*}{ Lava o látex com ABD ou SF após o final da aspiração } & SIM & 18 & 05,75 & 218 & 69,65 & 236 & 75,40 \\
\hline & NÃO & 10 & 03,19 & 67 & 21,41 & 77 & 24,60 \\
\hline & TOTAL & 28 & 08,95 & 285 & 91,05 & 313 & 100,00 \\
\hline \multirow{3}{*}{$\begin{array}{l}\text { Protege o látex após aspiração com embalagem limpa e } \\
\text { seca }\end{array}$} & SIM & 26 & 08,31 & 236 & 75,40 & 262 & 83,71 \\
\hline & NÃO & 02 & 00,64 & 49 & 15,65 & 51 & 16,29 \\
\hline & TOTAL & 28 & 08,95 & 285 & 91,05 & 313 & 100,00 \\
\hline \multirow{3}{*}{ Lava as mãos após o procedimento } & SIM & 21 & 06,71 & 135 & 43,13 & 156 & 49,84 \\
\hline & NÃO & 07 & 02,24 & 150 & 47,92 & 157 & 50,16 \\
\hline & TOTAL & 28 & 08,95 & 285 & 91,05 & 313 & 100,00 \\
\hline
\end{tabular}


Como pode ser visto no Quadro 04, das 285 aspirações realizadas naqueles pacientes que tiveram PAVM, em 227 (72,52\%) os profissionais não lavaram as mãos antes do procedimento.

Esses resultados contradizem o que é preconizado pela literatura, quando afirma que as mãos devem ser lavadas sempre antes e após qualquer procedimento, independente do uso de luvas, pois estas são o principal meio de transmissão das infecções hospitalares.(CDC, 1997, ANVISA, 2000, BLOM; LIMA, 2003).

GONZÀLEZ et al (2004), em estudo realizado com enfermeiras sobre a técnica de aspiração, encontraram dados semelhantes, quando observaram que somente $56 \%$ delas lavavam as mãos antes do procedimento. As autoras atribuem o fato a algumas crerem que ao usar luvas já estão utilizando uma barreira contra a infecção, o que é um conceito errôneo, já que está demonstrado que o uso de luvas não substitui a lavagem das mãos.

No que se refere à interrupção da dieta enteral antes da aspiração, nos pacientes que tiveram PAVM, das $165(93,75 \%)$ vezes que foi administrada em 134 vezes $(76,14 \%)$ esta não foi interrompida.

Sobre esse aspecto, vários autores como o CDC (1997); OLIVEIRA, ARMOND, TEDESCO (2001); COLOMBRINI et al (2003) advertem que a nutrição enteral deve ser interrompida durante o procedimento de aspiração, para prevenir vômitos e aspiração broncopulmonar.

Quanto ao uso de EPIs, das 285 (91,05\%) que foi realizado o procedimento de aspiração nos pacientes que tiveram PAVM, 264 vezes $(84,35 \%)$ os profissionais não usaram essa medida de profilaxia, isto é, não utilizaram todos os equipamentos durante a aspiração, que compreendem luvas, gorros, óculos, máscaras e capotes.

Em relação ao uso dos óculos, o Ministério da Saúde diz que devem ser usados durante os procedimentos passíveis de respingo de sangue ou de fluidos corpóreos nas mucosas oral, nasal e ocular do profissional (BRASIL, 1999).

Sobre esse item, GONZÁLEZ et al (2004) obtiveram dados semelhantes, quando avaliaram a competência prática de enfermeiros sobre aspiração. Identificaram nesse estudo que as enfermeiras na teoria consideravam o uso dos óculos necessário, porém, na prática, não os utilizaram.

Quanto ao uso do capote, ele é utilizado, porém os profissionais vestem no início do plantão, só retirando no final. O mesmo capote é utilizado em todos os procedimentos realizados e em diferentes pacientes. Essa prática contradiz as recomendações de pesquisadores, os quais afirmam que este deve ser imediatamente retirado após o uso e que caso necessite fazer procedimentos em pacientes diferentes deve substituí-lo para evitar infecções cruzadas (GOMES, 2003; PEREIRA et al, 2004).

Em relação ao uso de luvas estéreis nos pacientes que tiveram PAVM, a grande maioria, 273 vezes $(87,22 \%)$, fez uso desse passo. Ressaltamos que mesmo sendo essa técnica uma medida profilática no controle das infecções, foram usadas luvas de procedimento não estéril por 12 vezes $(3,83 \%)$.

Das 285 (91,05\%), em 281 (89,78\%) foi usado cateter de aspiração estéril. OLIVEIRA, ARMOND \& TEDESCO (2001) afirmam que o catéter de aspiração traqueal pode introduzir microorganismos no trato respiratório baixo. Portanto, deve ser estéril e de uso único.

No que diz respeito seguir a seqüência da aspiração (tubo, nariz e boca), em 242 (77,32\%) das $285(91,05 \%)$ os profissionais seguiram os passos preconizados por alguns autores (OLIVEIRA, ARMOND \& TEDESCO, 2001). A ANVISA (2000) recomenda que quando houver necessidade de aspirar a boca do paciente intubado, esse procedimento deve ser realizado usando uma nova sonda após aspiração traqueal.

Das $203(93,55 \%)$ vezes que foi utilizada gaze para limpar as secreções do cateter durante a aspiração, em 181 (83,41\%) estava estéril. É importante ressaltar que alguns profissionais usaram os invólucros das luvas para limpar as secreções.

A instilação de Soro Fisiológico (SF) para fluidificar as secreções no nosso estudo, das 238 $(91,18 \%)$ vezes, essa solução foi utilizada em 216 $(82,76 \%)$ era estéril.

SOLE et al (2003), em uma ampla avaliação em 27 hospitais dos Estados Unidos, com 1.665 enfermeiras e fisioterapeutas respiratórios, observaram que $74 \%$ dos centros estudados incluíam nos protocolos a instilação de SF quando as secreções estavam espessas.

THOMPSON (2000) \& DREYER; ZUNIGÃ (2003) afirmam que a instilação de solução salina pode ter efeito adverso na Saturação de Oxigênio $\left(\mathrm{SaO}_{2}\right)$, além do risco de infecção, não devendo ser utilização como rotina. Nesse mesmo aspecto, COLOMBRINI et al (2003) ressaltam que a instilação com SF, além de causar hipoxemia e infecções, pode prejudicar o bemestar psicológico do paciente. Para prevenir a oclusão do tubo traqueal é recomendado fazer a umidificação dos gases inspirados e hidratar o paciente adequadamente.

Das $84(92,31 \%)$ das vezes que foi necessária a utilização de ambu estéril ou desinfectado, em 60 $(65,93 \%)$ esse artefato estava estéril. FERNANDES, ZAMORANO \& TOREZAN FILHO (2000) ressaltam que o ambu é usado para ventilar o paciente intubado, em 
situações de urgência, durante o transporte, para hiperinsuflação nos intervalos das aspirações das VAS e na fisioterapia respiratória; para tanto deverá estar estéril ou desinfectado.

Acrescentando a esses dados, HINRICHSEN (2004) ressalta que as secreções depositadas nesse equipamento podem ser aerolizadas para dentro da árvore traqueobrônquica do paciente ou contaminar as mãos da equipe de atendimento, favorecendo a contaminação cruzada.

Quanto a descartar o catéter após sua utilização, em $267(85,30 \%)$ ele foi descartado, outras 18 vezes $(5,75 \%)$ deixaram o catéter conectado no látex e pendurado no frasco de aspirador, o que poderia contaminar os outros materiais que estão sendo utilizados ou mesmo o chão; no que se refere a lavar o látex com $A B D$ ou $S F$ no final do procedimento, do total das aspirações em 218 vezes $(69,65 \%)$ foi realizado de maneira correta.

Quanto a proteger o látex com embalagem limpa e seca após aspiração, das 285 (91,05\%) vezes, em $236(75,04 \%)$ esse preceito foi seguido. Essa técnica visa evitar a contaminação do ambiente (DREYER et al, 2003).

No que se refere à lavagem das mãos após o procedimento, das 285 vezes que esse procedimento foi realizado, em 135 vezes (43,13\%) os profissionais não cumpriram esse passo essencial na prevenção de infecções.

Em relação a informar ao paciente previamente à aspiração, percebemos que dos 285 procedimentos $(91,05 \%)$ em 264 vezes (84,35\%) essa ação não foi realizada. GONZÁLEZ (2004) concorda sobre o fato das enfermeiras na teoria acharem que devem informar ao paciente previamente sobre o procedimento, um pequeno número não o fez na prática. As autoras atribuem esse dado ao fato de que a alteração do nível de consciência e o menor grau de comunicação das enfermeiras com esse paciente as levam a tomar esse tipo de atitude.

Em relação a $\mathrm{FiO}_{2}$ ser dobrada ou elevada a $100 \%$ antes da aspiração, observamos nas 285 aspirações, esse procedimento não foi realizado em 255 (81,47\%). Sobre essa técnica DREYER et al (2003) salientam que devemos hiperoxigenar o paciente para prevenir hipoxemia agravando o seu quadro clínico.

Nesse estudo dos 285 (91,05\%) procedimentos realizados, por não haver catéter próprio para aspiração na instituição, foi usado sonda uretral de calibre adequado em 274 (87,54\%) vezes. No entanto, em 11 $(3,51 \%)$ esse catéter foi substituído por sonda nasogástrica ou mesmo sonda uretral de calibre maior ou menor do que o recomendado para o paciente.

Ressaltamos que os autores consultados recomendam que o cateter ou sonda deve ser macio, de material transparente, com ponta arredondada e múltiplos orifícios em contra-abertura na extremidade distal, que possua válvula digital para controle de pressão do vácuo e que o diâmetro externo não exceda $1 / 3$ do diâmetro interno do tubo endotraqueal ou traqueóstomo (SAMPAIO \& FARIA, 1998; COSTA, 1999; THE ROYAL FREE HAMPSTEAD NHS TRUST, 1999; PASSOS et al, 2000; THOMPSON, 2000; GONZÁLEZ et al, 2004).

Em relação à observação sobre se o ventilador era conectado ao paciente nos intervalos de aspiração, vimos que de um total de 285 vezes (91,05\%), em 235 $(75,08 \%)$ vezes esse procedimento foi realizado de forma correta, isto é, o paciente era ventilado em intervalos para então reintroduzir o catéter e aspirar outra vez, evitando, assim, a hipóxia.

Por outro lado, observamos que em relação ao tempo de aspiração em $183(64,21 \%)$ vezes os profissionais excederam os 15 segundos de permanência da sonda na traquéia, preconizados pela literatura (COSTA, 1999; THE ROYAL FREE HAMPSTEAD NHS TRUST, 1999; THOMPSON, 2000; OLIVEIRA, ARMOND \& TEDESCO, 2001; PASSOS et al, 2000; GONZÁLEZ et al, 2004). Nesse estudo, o tempo mínimo de aspiração das secreções foi de cinco segundo e o máximo de um minuto e trinta segundos.

Quanto a retornar a FiO2 inicial após a aspiração, das 30 vezes $(96,77 \%)$ em que foi elevada, em $22(70,97 \%)$ vezes esse procedimento foi realizado. Alguns autores salientam que concentração muito elevada de oxigênio pode levar a efeitos tóxicos, como alterações da fisiologia normal, depressão da respiração, diminuição da eritropoiese e débito cardíaco, vasodilatação pulmonar, vasoconstrição sistêmica, alteração da formação de surfactante, efeitos citotóxicos e traqueobronquite (DAVID et al, 2000; SMELTZER \& BARE, 2002).

No que se refere a anotações das aspirações no prontuário, 64,86\% não foram anotados. OCHOAVIGO, PACE \& SANTOS (2003) salientam a importância dos registros de enfermagem no prontuário, informando que os mesmos devem incluir a declaração dos problemas freqüentemente referidos pelos pacientes, os diagnósticos de enfermagem, os tratamentos e as respostas tanto à assistência médica como à de enfermagem, expressando o reflexo da avaliação periódica do paciente.

Do total das 285 (91,05\%) aspirações, 138 $(44,41 \%)$ foram realizadas pelos técnicos de enfermagem, $67(21,41 \%)$ auxiliar de enfermagem. RIBEIRO \& PEDRÃO (2005) ressaltam que o pessoal de nível médio, apesar de ser o menos qualificado, é executor da maior parte das ações na assistência direta aos pacientes internados e que necessitam de cuidados intensivos. Quanto ao enfermeiro, mesmo em unidades 
que prestam cuidado à pacientes graves, continua delegando tarefas, atuando mais na administração da unidade do que nos cuidados direto ao paciente.

Tabela 01 - Distribuição do número de trocas dos dispositivos por dias de permanência dos 17 pacientes com VM no estudo - Natal/RN, 2005.

\begin{tabular}{|c|c|c|c|c|c|c|c|c|}
\hline \multirow{3}{*}{$\begin{array}{l}\text { Permanência } \\
\text { no estudo } \\
\text { (em dias) }\end{array}$} & \multicolumn{8}{|c|}{ MATERIAIS } \\
\hline & \multicolumn{2}{|c|}{ PACIENTES } & \multicolumn{2}{|c|}{$\begin{array}{l}\text { ASPIRADORES } \\
\text { (FRASCOS) }\end{array}$} & \multicolumn{2}{|c|}{ UMIDIFICADORES } & \multicolumn{2}{|c|}{ LÁTEX } \\
\hline & $\mathbf{N}$ & $\%$ & $\mathrm{~N}$ & $\%$ & $\mathbf{N}$ & $\%$ & $\mathbf{N}$ & $\%$ \\
\hline $03 \mid-105$ & 06 & 35,29 & 02 & 12,50 & 01 & 16,67 & 03 & 16,67 \\
\hline $06 \mid-108$ & 07 & 41,18 & 07 & 43,75 & 01 & 16,67 & 05 & 27,78 \\
\hline $09|-| 11$ & 04 & 23,53 & 07 & 43,75 & 04 & 66,67 & 10 & 55,56 \\
\hline TOTAL & 17 & 100,00 & 16 & 100,00 & 06 & 100,00 & 18 & 100,00 \\
\hline
\end{tabular}

Na Tabela 01, vemos que os 17 pacientes estudados permaneceram no estudo de 03 a 11 dias com uma média de 6,65.

Em relação às trocas dos frascos do aspirador, vemos que nos pacientes que permaneceram de 03 a 05 dias esse procedimento foi realizado 06 vezes $(35,29 \%)$; entre 06 a 08 dias aconteceram 7 trocas $(41,18 \%) ; \quad$ naqueles pacientes com tempo de permanência entre 09 a 11 dias foram trocados 4 vezes $(23,53 \%)$.

A troca de látex foi realizada 03 vezes $(22,69 \%)$ naqueles pacientes que permaneceram no estudo entre 03 a 05 dias; 05 (27,78\%) vezes dentre 06 a 08 dias; 10 trocas $(55,56 \%)$ naqueles com 09 a 11 dias.

A ANVISA (2000) recomenda que os frascos que acondicionam a secreção, assim como as extensões dos aspiradores, deverão ser lavados diariamente com solução detergente, e submetidos à desinfecção de alto nível ou à esterilização na saída do paciente.

HINRICHSEN (2004) orienta que é importante limpar o aspirador, esvaziar o frasco quando atingir dois terços de sua capacidade ou a cada 12 horas, evitando o retorno das secreções para o paciente na hora da aspiração, contaminando sua árvore traqueobrônquica ou mesmo os equipamentos e/ou materiais. Acrescenta que o frasco do aspirador junto com o látex deverá ser trocado por outro estéril a cada 12 horas.

Quando observamos os dados acerca dos umidificadores, vemos que a troca aconteceu $01 \mathrm{vez}$ $(16,67 \%)$ em paciente que permaneceu no estudo de 03 a 05 dias e entre 06 a 08 dias respectivamente; 04 trocas $(66,67 \%)$ entre 09 a 11 dias.

A ANVISA (2000) recomenda que os umidificadores e seus respectivos reservatórios e extensões devem ser trocados pelo menos a cada 24 horas e substituídos por outros desinfetados ou esterilizados.

Nesse estudo o paciente permanece em alguns casos com o mesmo equipamento até sua alta, ou foram trocados apenas na ocorrência de algum problema nos dispositivos ou na presença de grandes sujidades. Vemos que o látex foi o acessório mais trocado, seguido dos aspiradores. Os umidificadores foram os menos trocados.

HINRICHSEN (2004) afirma que os nebulizadores podem ser contaminados pelas mãos dos profissionais, por fluidos não-estéreis adicionados no reservatório, retrogradamente pelo paciente ou por inadequada esterilização ou desinfecção entre usos, produzindo aerossóis transportadores de bactérias, causando pneumonias. 
Tabela 02 - Distribuição dos passos realizados segundo a fisioterapia respiratória e nutrição enteral - Natal/RN,

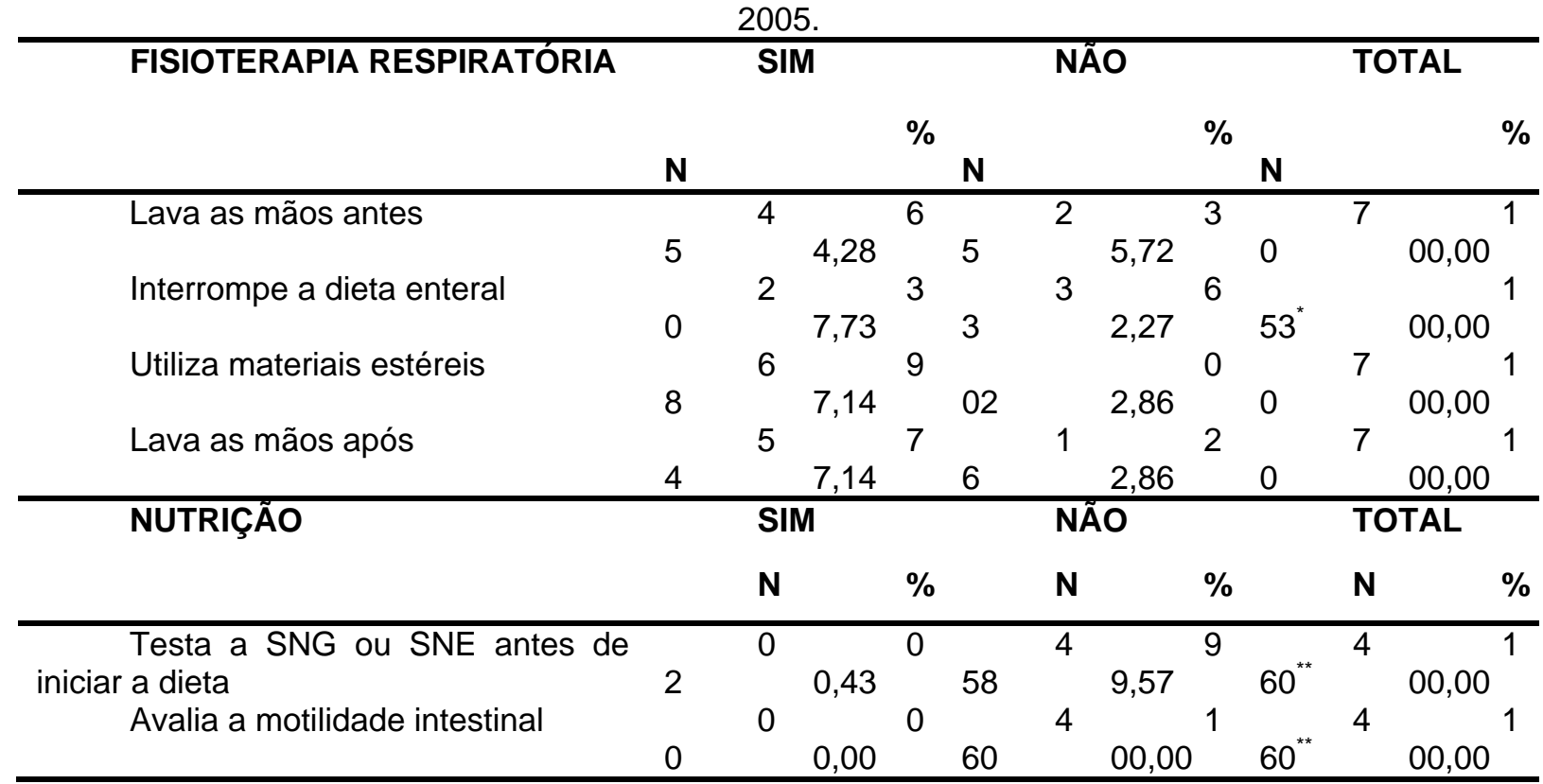

* 17 pacientes estavam sem dieta.

** Durante o dia eram administradas 5 dietas: $7 \mathrm{~h}, 11 \mathrm{~h}, 14 \mathrm{~h}, 18 \mathrm{~h}$ e $22 \mathrm{~h}$.

Quanto à fisioterapia respiratória, observamos na Tabela 02 que, em 70 procedimentos realizados, em 45 $(64,28 \%)$ os profissionais lavaram as mãos antes da fisioterapia; 33 (62,27\%) não interrompem a dieta durante as manobras fisioterápicas; em 68 procedimentos $(97,14 \%)$ os materiais utilizados estavam estéreis e 54 vezes $(77,14 \%)$ os profissionais lavaram as mãos após realização das manobras. Salientamos que todos os 17 pacientes fizeram fisioterapia.

Ressaltamos, porém, que é prática comum desses profissionais, ao término das manobras fisioterápicas, colocarem luvas estéreis por cima daquelas que estão sendo utilizadas, e daí aspirar as secreções traqueobrônquicas. Esse hábito peculiar induz a um sério risco de contaminação das luvas estéreis e conseqüente do material de aspiração. Fere também os princípios da prevenção das infecções que preconiza a lavagem das mãos antes e após a execução de cada procedimento, independente do uso de luvas (GOMES, 2003).

No que se refere à nutrição, vimos que não há nenhum cuidado quanto à testagem da SNG ou SNE antes de iniciar a dieta e muito menos avaliar a motilidade intestinal através da ausculta e medida de volume gástrico para prevenção da broncoaspiração, como preconizado pelo CDC (1997) e ANVISA (2000). Resultou, portanto, nesse que das 460 vezes que foi administrado a alimentação enteral, apenas em 02 $(0,43 \%)$ esse procedimento foi realizado. Salientamos que, dos 17 pacientes, 15 fizeram uso de dieta enteral.

Tabela 03 - Distribuição dos dias de permanência dos 17 pacientes estudados e a mudança de decúbito por turno. PSCS - Natal/RN, 2005.

\begin{tabular}{ccccccc}
\hline \multirow{2}{*}{$\begin{array}{c}\text { Permanência no estudo } \\
\text { (em dias) }\end{array}$} & \multicolumn{2}{c}{ MANHÃ } & MUDANÇA DE DECÚBITO & \multicolumn{2}{c}{ NOITE } \\
& $\mathbf{N}$ & $\mathbf{\%}$ & $\mathbf{N}$ & $\mathbf{0}$ & $\mathbf{N}$ & $\%$ \\
\hline $03|-| 05$ & 22 & 19,30 & 08 & 25,81 & 13 & 27,66 \\
$06|-| 08$ & 51 & 44,74 & 12 & 38,71 & 22 & 46,81 \\
$09|-| 11$ & 41 & 35,96 & 11 & 35,48 & 12 & 25,53 \\
\hline TOTAL & $\mathbf{1 1 9}$ & $\mathbf{1 0 0 , 0 0}$ & $\mathbf{3 6}$ & $\mathbf{1 0 0 , 0 0}$ & $\mathbf{4 7}$ & $\mathbf{1 0 0 , 0 0}$ \\
\hline
\end{tabular}


Quando relacionamos os dias de permanência dos pacientes por dias no estudo com o número de mudanças de decúbito por turno, de acordo com a Tabela 03 , percebemos que o horário da manhã apresentou uma maior freqüência. Os 06 pacientes que permaneceram de 03 a 05 dias foram mobilizados 22 vezes (19,30\%); entre 06 a 08 (07 pacientes) esse procedimento foi realizado 51 vezes $(44,74 \%)$. Os demais (04 pacientes) com uma permanência entre 09 a 11 dias, 41 vezes (35.96\%). Identificamos, pois, que esses pacientes foram mobilizados pelo menos uma vez nesse horário e que o horário da tarde obteve a freqüência mais baixa.

Justificamos o fato da mudança de decúbito acontecer com maior freqüência pela manhã devido à higienização dos pacientes ocorrerem nesse horário. Mesmo assim, essa freqüência está abaixo das necessidades, pois esse procedimento deve ocorrer a cada duas horas, como é preconizado pelos autores consultados (CDC, 1997; COSTA, 1999; SMELTZER \& BARE, 2002).

Segundo DUCKER (2002), a imobilidade física pode produzir três mudanças críticas na capacidade de adaptação do sistema cardiovascular na condução do sangue para os capilares. A primeira é o controle vasomotor, a segunda é o retorno venoso ao coração e a última é a estase venosa, ocasionando formação de trombose venosa.

O mesmo autor ressalta que os danos ao aparelho respiratório são grandes, como compressão torácica decorrente do posicionamento ou distensão abdominal e a inadequação do uso da musculatura responsável pela respiração. Todas essas complicações respiratórias podem causar ao organismo inúmeros desequilíbrios, muitas vezes fatais. Em decorrência dos distúrbios respiratórios, a troca gasosa realizada no pulmão fica prejudicada, assim como o suprimento de oxigênio aos tecidos e órgãos do organismo; além do acúmulo de secreção pulmonar, podendo levar a infecções.

Quanto a manter o paciente com a cabeceira elevada, observamos que os internados na UTI permaneciam todos com cabeceira elevada a $30^{\circ}$ ou $45^{\circ}$, enquanto os que estavam nos setores de urgência muitas vezes permaneciam com a cabeceira a $0^{\circ}$ pelo motivo de se encontrar em uma maca e esta, às vezes, a cabeceira era impossível de ser elevada.

Alguns autores afirmam que, se não houver contra-indicação, a cabeceira do leito deve ser elevada a ângulo de $30^{\circ}$ a $45^{\circ}$ como medida para evitar a pneumonia aspirativa em pacientes com ventilação mecânica e com tubo de nutrição enteral. Afirmam, também, que essa medida tem como finalidade evitar a pressão sobre as proeminências ósseas (CDC, 1997;
COSTA, 1999; SMELTZER \& BARE, 2002; DUCKER, 2002).

\section{CONCLUSÃO}

Esse estudo possibilitou identificar a incidência da VM e da PAVM e observar os procedimentos realizados pela equipe de enfermagem, médica e de fisioterapia relacionados ao paciente intubado em VM. Forneceu dados para identificarmos a existência da associação entre a VM e o aparecimento de pneumonias em pacientes que necessitam desse procedimento em um hospital de referência da Grande Natal-RN e chegamos às seguintes conclusões:

No que se refere à incidência da VM e PAVM e a caracterização dos pacientes que participaram do estudo: dos 38 pacientes que foram intubados durante o período da pesquisa, $35(92,10 \%)$ utilizaram ventilador mecânico, sendo que, 17 (44,74\%) foram a óbito e $04(10,52 \%)$ extubados antes de completarem 48 horas de internamento, não sendo possível, portanto, fazer o diagnóstico de PAVM; dos 17 $(44,74 \%)$ que permaneceram no estudo por mais de 48 horas, período necessário para fazer esse diagnóstico, $13(76,47 \%)$ tiveram PAVM, a maioria era do sexo masculino (82,35\%), com idade entre 55 a 64 anos $(23,53 \%)$, não alfabetizados $(35,30 \%)$ e diagnóstico médico de AVC (47,06\%).

No que se refere à caracterização dos profissionais que participaram do estudo: a categoria predominante foi o técnico de enfermagem $(32,35 \%)$, do sexo feminino $(69,12 \%)$, com nível médio de escolaridade $(51,47 \%)$, entre 40 a 50 anos de idade (44,12\%); com tempo de serviço de 05 a 09 anos e a maior parte exerciam suas funções na UTI.

No que se refere à identificação dos cuidados prestados pela equipe relacionados à $\mathrm{VM}$, observamos que: dos 35 ventiladores mecânico montados, em 25 $(71,43 \%)$ não foi realizada a limpeza e desinfecção antes da montagem; $21(60,00 \%)$ não foram montados com técnica asséptica; somente 29 ventiladores $(82,86 \%)$ foram testados; destes, $27(93,11 \%)$ o pulmão de teste usado não estava estéril; após montado a conexão $Y$ foi protegida por 27 vezes $(77,15 \%)$ com material não estéril; foi colocado o rótulo com data e assinatura de quem montou em 18 ventiladores $(51,43 \%)$; o umidificador ficou vazio por 30 vezes $(85,71 \%)$ logo após a montagem; no momento da instalação o ventilador foi testado em 29 vezes (82,86\%), destas o pulmão não estava estéril em 26 $(87,00 \%)$; das 30 vezes que a água foi colocada no momento da instalação do aparelho no paciente, em 18 $(60,00 \%)$ estava estéril e $12(40,00 \%)$ foi utilizado água de torneira, solução salina ou ringer simples; durante a VM, das 87 vezes que havia presença de condensado, 
ele foi descartado em $70(80,45 \%)$ e as mãos não foram lavadas após esse procedimento em 52 vezes $(74,28 \%) ; \quad$ a água utilizada na reposição dos umidificadores estava estéril em 58 vezes (84,05\%), porém o líquido remanescente nunca foi desprezado e sim completado; durante todo período do estudo, os circuitos dos ventiladores não foram trocados; os ventiladores mecânicos foram montados 26 vezes $(74,29 \%)$ por enfermeiro e $09(25,71 \%)$ foi por auxiliar de enfermagem; durante as 17 intubações endotraqueais, naqueles pacientes que passaram mais de 48 horas de estudo, em $100 \%$ dos procedimentos o material estava armazenado em condições adequadas e mantinha-se no prazo de validade; em 11 vezes $(64,71 \%)$ os profissionais não lavaram as mãos antes do procedimento; $100 \%$ dos profissionais não utilizaram EPI; em 16 procedimentos $(94,12 \%)$ foi utilizado luvas estéreis; o cuff foi testado com seringa estéril em $100 \%$ das vezes; o fio guia foi utilizado em 15 intubações e em 11 (73,33\%) ele estava estéril; em 08 pacientes $(47,06 \%)$ houve tentativa de introdução do TOT sem êxito, desses, $06(75,00 \%)$ o tubo continuou sendo usado; 12 pacientes $(93,31 \%)$ as luvas após terem sido contaminadas continuaram sendo utilizadas; o cuff foi inflado 12 vezes (70,59\%) com seringa estéril; as mãos foram lavadas após a intubação em 12 vezes (70,59\%).

Quanto à aspiração das VAS, observamos que das 313 realizadas, $249(79,55 \%)$ os profissionais não realizaram lavagem prévias das mãos; foram realizadas 176 dietas, em 141 vezes $(80,11 \%)$ não foi interrompida durante a aspiração; em 264 vezes (94,35\%) os profissionais não utilizaram todos os EPIs; 298 vezes $(95,21 \%)$ os profissionais utilizaram luvas estéreis; 309 $(98,72 \%)$ foi usado catéter de aspiração estéril; 266 $(84,98 \%)$ foi seguida a seqüência de aspiração (tubo, nariz e boca); das 217 vezes que foi utilizado gaze para limpar as secreções, em 191 (83,41\%) era estéril; mesmo sendo incorreto o uso do SF, este foi utilizado por 261, em 232 (88,89\%) estava estéril; das 91 vezes que foi necessário à utilização de ambu, em 67 $(73,63 \%)$ estava estéril; o catéter foi descartado após sua utilização, em 293 (93,61\%); a lavagem do látex com ABD e SF no final da aspiração ocorreu em 236 vezes (75,40\%); em 262 vezes $(83,71 \%)$ o látex foi protegido com embalagem limpa e seca; as mãos foram lavadas, após o procedimento, em menos da metade, 156 vezes $(49,84 \%) .138(44,41 \%)$ foram realizadas pelos técnicos de enfermagem, $67(21,41 \%)$ auxiliar de enfermagem, 69 (22,04\%) fisioterapeuta, 09 (2,88\%) enfermeiro e $01(0,32 \%)$ pelo médico; independente do número de dias de permanência, os frascos de aspiradores foram trocados somente de 2 a 7 vezes; os látex de 01 a 04 vezes; os umidificadores de 3 a 10 dias. A desinfecção dos nebulizadores de pequeno volume era realizada somente 1 vez ao dia; quanto à fisioterapia respiratória, foram realizadas 70 procedimentos, desses, em 45 (64,28\%) os profissionais não realizaram lavagem prévia das mãos; $33(62,27 \%)$ não interromperam a dieta durante as manobras; $68(97,14 \%)$ os materiais utilizados estavam estéreis; $54(77,14 \%)$ os profissionais lavaram as mãos após o procedimento; quanto à administração da dieta enteral, não há nenhum cuidado quanto à testagem ou avaliação da motilidade intestinal antes de sua administração; no que se refere à mudança de decúbito, os pacientes eram mobilizados no máximo três vezes ao dia, predominando no horário da manhã.

No que se refere à identificação da existência de associação entre a VM e o aparecimento de pneumonias em pacientes que necessitam desse procedimento: detectamos que dos 17 pacientes que foram submetidos à VM, $13 \quad(76,47 \%)$ tiveram diagnóstico de PAVM , sendo que $04(30,77 \%)$ com 72 horas e $09(69,23 \%)$ após esse tempo; o meio diagnóstico mais utilizado foi a cultura de secreção traqueal $(76,92 \%)$.

Sabemos que inúmeros fatores podem contribuir para que o paciente tenha PAVM, como vimos na literatura. Porém, mesmo não podendo afirmar que a pneumonia ocorreu devido ao uso inadequado dos passos na realização dos cuidados nos pacientes com VM, estamos convictos de que a falta de diretrizes são fatores que sinalizam o risco para que esses pacientes desenvolvam PAVM e mesmo para aqueles que por outras razões não tiveram pneumonia.

\section{REFERÊNCIAS BIBLIOGRÁFICAS}

AGUILLERA, J.C.G.; ORTíZ, A.A. Neumonía nosocomial em la unidad de cuidados intensivos. Revista cubana de medicina. v.36, n.2, p.100-105. 1996.

ALMEIDA, M.C.P. et al. O trabalho da enfermagem. São Paulo: Cortez, 1997.

ANVISA. Agência Nacional de Vigilância Sanitária. Curso básico de controle de infecção hospitalar. Caderno B: principais síndromes infecciosas hospitalares. Brasília, 2000, [online] Disponível em: $<$ http://www.cvs.saude.sp.gov.br/pdf/ClHCadernoB.pdf $>$ [Acesso em 18 mai. 2004].

BEZERRA, S.V. Acidentes de trabalho panorama vivenciado pelos profissionais de enfermagem em um Hospital Estadual em Natal - RN, 1999. Natal, 2000. 97p. Dissertação (Mestrado). Universidade Federal do Rio Grande do Norte.

BEZERRA, V.N.P.; PEREIRA, M.L.D. Utilização de Equipamento de proteção individual pela equipe de enfermagem na unidade clínico-cirúrgica. Revista da Rede de Enfermagem do Nordeste. v.5, n.1, p.56-61, 2004. 
BLOM, B.C.; LIMA, S.L. Lavagem das mãos. In: COUTO, R.C.; PEDROSA, T.M.G.; NOGUEIRA, J.M. Infecção hospitalar e outras complicações nãoinfecciosas da doença: epidemiologia, controle e tratamento. $3^{a}$ ed. Rio de Janeiro: Medsi, 2003. p.481496.

BRASIL. Ministério da Saúde. Portaria ministerial $N^{0}$ 2616, 12 de maio de 1998. Expede em forma de anexos, normas para o controle de Infecção Hospitalar. Diário Oficial da União. Brasília, [online] 1999. Disponível

em:

http://www.ccih.med.br/portaria2616.html [Acesso em 18 mai. 2004].

BRASIL. Ministério da Saúde. Coordenação Nacional de DST e AIDS. Manual de condutas: exposição ocupacional a material biológico: hepatite e HIV. Brasília; 1999.

BRASIL. Ministério da Saúde. Comissão Nacional de Ética em Pesquisa. Normas para pesquisa envolvendo seres humanos (Res. CNS 196/96 e outras). Brasil, Brasília, 2000. (Série cadernos técnicos).

BRASIL. Ministério da Saúde. Anuário estatístico de saúde no Brasil. [online] 2001. Disponível em: http://portal.saude.gov.br/portal/aplicacoes/anuario2001 lindex.cfm?saude=http\%3A\%2F\%2Fportal.saude.gov.br \%2Fportal\%2Faplicacoes\%2Fanuario2001\%2Findex.cf m\&obj=\%24VObj\&botaook=OK [Acesso em 20 de mar. 2005].

BRASIL. Ministério da Educação. Instituto Nacional de Estudos e pesquisas Educacionais Anísio Teixeira (INEP). Mapa de analfabetismo no Brasil. Brasília, [online] 2003. Disponível em:

http://www.publicacoes.inep.gov.br/arquivos/\%7B3D805 070-D9D0-42DC-97AC-

5524E567FC02\%7D MAPA\%20DO\%20ANALFABETIS MO\%20NO\%20BRASIL.pdf [Acesso em 30 de jan. 2005].

CAVALCANTE, N.J.F. et al . Unidade de terapia intensa. In: FERNANDES, A.T. Infecção hospitalar e suas interfaces na área da saúde. São Paulo: Atheneu, 2000, p.749-770.

CAVALCANTI, I.; HINRICHSEN, S.L. Infecção hospitalar: importância e controle. In: HINRICHSEN, S.L. Biossegurança e controle de infecções: risco sanitário hospitalar. Rio de Janeiro: Medsi, 2004, p.273281.

CDC. Centers for Diseases Control and Prevention. Guidelines for prevention of nosocomial pneumonia. v.46; jan. 1997.

COLOMBRINI, M.R.C. et al. Assistência de enfermagem a pacientes em ventilação mecânica. In: ZUÑIGA, Q. G. P. Ventilação mecânica básica para enfermagem. São Paulo: Atheneu, 2003, p.51-56.

COFEN. Conselho Federal de Enfermagem. Portal Cofen. [online] 2005. Disponível em: http://www.portalcofen.gov.br/2007/ [Acesso em 10 de abr. 2005].

COSTA, D. Fisioterapia respiratória básica. São Paulo: Atheneu, 1999.

DAVID, C.M.N. et al (Org.). Complicações da ventilação mecânica. II Consenso Brasileiro de Ventilação Mecânica. Jornal de pneumologia. v.26, supl. 2, p.4562, 2000.

DREYER, E.; ZUÑIGA, Q.G.P. Ventilação mecânica. In: CINTRA, E.A.; NISHIDE, V.M.; NUNES, W.A. Assistência de enfermagem ao paciente gravemente enfermo. 2 ed. São Paulo: Atheneu, 2003, p.351-366.

DREYER, $E$. et al. Técnicas de enfermagem na ventilação mecânica. In: ZUÑIGA, Q.G.P. Ventilação mecânica para enfermagem. São Paulo: Atheneu, 2003, p.41-49.

DUCKER, A. Pressure ulcer: assessment, prevention and compliance. TCM. p.61-65, 2002.

FERNANDES, A.T.; RIBEIRO FILHO, N.; BARROSO, E.A. Conceito. Cadeia epidemiológica das infecções hospitalares e avaliação custo-benefício das medidas de controle. In: FERNANDES, A.T. (Org.). Infecção hospitalar e suas interfaces na área da saúde. São Paulo: Atheneu, 2000, p.215-265.

FERNANDES, A.T.; ZAMORANO, P.O.; TOREZAN FILHO, M.A. Pneumonia hospitalar. In: FERNANDES, A.T. (Org.). Infecção hospitalar e suas interfaces na área da saúde. São Paulo: Atheneu, 2000a, p.516-555. GOLDWASSER, R. et al (Cood). Desmame. II Consenso Brasileiro de Ventilação Mecânica. Jornal de pneumologia. v.26, supl.2, p.54-60, 2000.

GOMES, D.L.C. Precauções e isolamento de pacientes. In: Infecção hospitalar e outras complicações nãoinfecciosas as doença: epidemiologia, controle e tratamento. Rio de Janeiro: Medsi, 2003, p.469-479.

GONZÁLEZ, N.A. et al. Avaliação da competência prática e dos conhecimentos científicos das enfermeiras de uma UCI sobre a aspiração endotraqueal. Cuidado Intensivo. v.1, n.4, p.7-17, nov. 2004.

HERNANDEZ P.G. et al. Prevención de la neumonía asociada a ventilación mecánica. Revista Chilena de Infectologia. [online] 2001. Disponível em: http://www.scielo.cl/scielo.php?script=sci arttext\&pid=S 0716-10182001018200004\&lng=pt\&nrm=iso\&tlng=es

[Acesso em 15 de ago. 2004].

HINRICHSEN, S.L. Aspectos éticos e jurídicos dos processos infecciosos hospitalares e suas relações com a vigilância e a qualidade assistencial. In: HINRICHSEN, S.L. Biossegurança e controle de infecções: risco sanitário hospitalar. Rio de Janeiro: Medsi, 2004, p.273-281.

LACERDA, R.A. O significado político-social das infecções hospitalares e seu controle para a saúde coletiva. In: FERNANDES, Antônio Tadeu (Org.). 
Infecção hospitalar e suas interfaces na área da saúde. São Paulo: Atheneu, 2000, p.1618-32.

MOURA, J.P. A adesão dos profissionais de enfermagem às precauções de isolamento na assistência aos portadores de microorganismos multiresistentes. Ribeirão Preto, 2004. Dissertação (Mestrado) - Escola de Ribeirão Preto - Universidade de São Paulo. [online] Disponível em: http://www.teses.usp.br/teses/disponiveis/22/22132/tde12082004-125447/publico/mestrado.pdf [Acesso em 14 de jan. 2005].

NICOLETE, M.G.P. Acidentes de Trabalho: um estudo do conhecimento e ocorrência acidentária entre trabalhadores de enfermagem de um hospital geral do Rio Grande do Norte. Natal, 2001. 169p. Tese (Doutorado) - Escola de Enfermagem de Ribeirão Preto - Universidade de São Paulo.

OCHOA VIGO, K.; PACE, A.E.; SANTOS, C.B. Análise retorspectiva dos registros de enfermagem em uma unidade especializada. Revista Latino-americana de enfermagem. v.11, n.2, 2003.

OLIVEIRA, A.L.M. et al. Acesso e manutenção das vias aéreas. II Consenso Brasileiro de Ventilação Mecânica. Jornal de pneumologia. v.26, sup.2, p.63-68, 2000.

OLIVEIRA, A.C; ARMOND, G.A.; TEDESCO, L.A. Procedimentos nas vias respiratórias. In: MARTINS, M.A. Manual de infecção hospitalar: epidemiologia, prevenção e controle. 2 ed. Rio de Janeiro: Medsi, 2001, p.343-353.

PASSOS, E. (coord.) et al. Papel da enfermagem na assistência ao paciente em ventilação mecânica. II Consenso Brasileiro de Ventilação Mecânica. Jornal de pneumologia. v.26, sup.2, p.27-34, 2000.

PAVELQUEIRES, S. et al. Trauma de Crânio. In: Manobras avançadas de suporte ao trauma. São Paulo: Legis Summa, 1997, p.91-99.

PEIXOTO, M.T.; GEOCONDA, M. Ressuscitação cardiopulmonar: assistência de enfermagem. Rio de Janeiro: Revinter, 1998, p.83-107.

PEREIRA, M.S. et al. Avaliação de serviços de apoio na perspectiva do controle de infecção hospitalar. Revista Eletrônica de Enfermagem. [online] 1999. Disponível em: http://www.fen.ufg.br/revista/revista1 1/03.htm. [Acesso em 15 de ago 2004].

PEREIRA, T.M. et al. Avaliação da adoção das medidas de precauções padrão em categorias específicas de profissionais de saúde. Revista Eletrônica de Enfermagem. [online] 1999. Disponível em: http://www.fen.ufg.br/revista/revista1 1/05.htm [Acesso em 15 de ago. 2004].

POLIT, D.F.; BECK, C.T.; HUNGLER, B.P. Fundamentos de pesquisa em enfermagem: métodos, avaliação e utilização. 5 ed. Porto Alegre: Artmed, 2004, 487 p.

RIBEIRO, M.I.L.C.; PEDRÃO, J.L. O ensino de enfermagem no Brasil: enfoque na formação de nível médio. Revista Nursing. v.82, n.8, p.125-128, 2005.

ROCHA, L.C.M. Infecções respiratórias. In: MARTINS, M.A. Manual de infecção hospitalar: epidemiologia, prevenção e controle. 2 ed. Rio de Janeiro: Medsi, 2001, p.190-199.

RODRÍGUEZ, R.M. et al. Neumonía nosocomial asociada a ventilación mecánica. Revista Cubana de Pediatria. v.74, n.3, p.222-232, 2002.

ROGERS, J.H.; OSBORN, H.H.; POUSADA, L. Enfermagem de emergência: manual prático. Porto Alegre: Artes Médicas, 1992.

SADER, H.S. et al. Sensibilidade a antimicrobianos de bactérias de bactérias isoladas do trato respiratório baixo de pacientes com infecções respiratórias adquiridas na comunidade: resultados brasileiros do programa SENTRY de Vigilância de resistência a antimicrobianos dos anos de 1997 e 1998. Jornal de Pneumologia. v.27, n.2, p.25-33, 2001.

SAMPAIO, L.A.B.N.; FARIA, M.de F.G. Atuação da enfermagem em ventilação mecânica. In: AMARAL, R.V.G.; AULER JÚNIOR, J.O.C. Assistência ventilatória mecânica. Rio de Janeiro: Atheneu, 1998, p.339-353.

SANTOS, A.A.M.S. Higienização das mãos no controle das infecções em serviços de saúde. [online] 2004. Disponível em

http://www.anvisa.gov.br/servicosaude/controle/higieniz acao mao.pdf [Acesso em 07 de dez. 2004].

SILVA, E.U.; NOGUEIRA, M.G.; PEIXOTO, M.L.B. Prevenção da pneumonia hospitalar. In: COUTO, R.C.; PEDROSA, T.G.; NOGUEIRA, J.M.. Infecção hospitalar e outras complicações não-infecciosas da doença: epidemiologia, controle e tratamento. 3 ed. Rio de Janeiro: Medsi, 2003, p.497-534.

SILVA, H.M.M.D. Ecos da experiência: os custos invisíveis da infecção hospitalar. Natal, 2000. 65 p. Dissertação (Mestrado). Universidade Federal do Rio Grande do Norte.

SMELTZER, S.C.; BARE, B.G. Brunner e Suddarth: tratado de enfermagem médico-cirúrgica. 9 ed. Rio de Janeiro: Guanabara Koogan, 2002, p.411-508.

SOLE, M.L. et al. A multisite survey of suctioning tecniques and airway management practices. American Journal of critical care. v.12, n.3, p.220-230, 2003.

THE ROYAL FREE HAMPSTEAD NHS TRUST. Guidelines for tracheal suction. [online] 1999. Disponível em: http://www.bahnon.org.uk/Professional\%20Guidelines/T rachealSuction.doc [Acesso em 09 de jan. 2005].

TEIXEIRA, P.J.Z. et al. Pneumonia associada à ventilação mecânica: impacto da multirresistência bacteriana na morbidade e mortalidade. Jornal 
Brasileiro de Pneumologia. [online] 2004. Disponível em:

http://www.scielo.br/pdf/ibpneu/v30n6/a09v30n6.pdf. [Acesso em 15 de ago. 2004].

THOMPSON, L. Tracheal Suctioning adults with na artificial airway. The joanna Briggs Intitute for evidence basead nursing and midwifery. Best practice. [online] 2000. Disponível em:

http://www.joannabriggs.edu.au/pdf/bpsuc.pdf [Acesso em 09 de jan. 2005].

TRYBA, M. Prophylaxis of stress ulcer bleending: a meta-analysis. Journal of clinical gastroenterology. v.13, n.2, p.44-45, 1991.

ZEITOUN, S.S. et al. Incidência de pneumonia associada à ventilação mecânica em pacientes submetidos à aspiração endotraqueal pelos sistemas aberto e fechado: estudo prospectivo - dados preliminares. Revista Latino-americana de enfermagem. v.9, n.1, p.46-52, 2001.

ZINN, G.R.; SILVA, M.J.P.; TELLES, S.C.R. Comunicar-se com o paciente sedado: vivência de quem cuida. Revista Latino-americana de enfermagem. v.11, n.3, p.326-332, 2003.

Artigo recebido em 10.07.2006

Aprovado para publicação em 29.12.2006 